ЯЖБОРОВСКАЯ Инесса Сергеевна - доктор исторических наук, профессор; главный научный сотрудник Института социологии Федерального научно-исследовательского социологического центра РАН (117218, Россия, г. Москва, ул. Кржижановского, 24/35, корп. 5, inessajaz@gmail.com)

\title{
ПОЛЬСКИЙ ЖУРНАЛ «ПОЛИТОЛОГИЧЕСКИЕ ИССЛЕДОВАНИЯ» О ПРОБЛЕМЕ «ВЫБОРЫ И ВЛАСТЬ»
}

\begin{abstract}
Аннотация. В статье анализируются результаты выборов в Польше, источники и механизмы монополизации власти в ходе парламентских и президентских выборов 2015 г., выборов в Европарламент в 2019 г., а также в парламент и правительство в 2019 г., в ходе которых происходило утверждение авторитаризма, фундаментализма и элементов тоталитаризма в этой стране. Автор обозначает стратегию и тактику монополизации власти, роль социотехники и индоктринации в изменении поведения населения, прочных изменений в структуре ценностей, эмоций и стереотипов и представляет роль популизма в ходе избирательных кампаний.
\end{abstract}

Ключевые слова: Польша, политические механизмы власти, выборы 2015-2019 гг.

$\mathrm{O}$ рган Варшавского университета «Политологические исследования» ${ }^{1}$ подводит итоги текущего избирательного цикла (в Республике Польша за четыре последних года выборы проводились пять раз). Анализируя их ход и результаты, редколлегия обозначила тему номера так: «Власть и выборы: между выбором и монополией». В этой классической сфере политологии она задалась вопросом: что же связывает между собой анализ механизмов выборов (имея в виду недавние конкретные) с проблематикой власти, кроме этой классической области знания (особенно если они действительно свободные, не являются объектом манипулирования и проходят не под дулом винтовки), и монополией власти, раз эта монополия является для окружающих отрицанием выбора?

Редколлегия сформулировала ряд важных, заслуживающих внимания методологических положений. Она напомнила, что общим знаменателем, последствия которого слишком редко осмысливаются, является, во-первых, факт, что при существующем в Польше строе выборы - это событие, а точнее, процесс конституирования центра власти, существенного с точки зрения как его легитимации, так и контроля и оценки обществом материализации политической альтернативы, осуществления перемен. Поэтому следует осмыслить не только то, что определило ход, колорит, атмосферу и формальные результаты выборов, но и то, исполняют ли они функцию обстоятельного контроля - подлинного выбора. То есть, делают ли они возможным и даже предопределяют ли иной путь, иной стиль правления и иное право на власть.

Во-вторых, выборы напоминают о существовании обратной связи (правда, редко сохраняющей симметрию) в области влияния выборов на то, кто и как правит, какой имеет на это мандат, каковы границы свободы действий и влияния правящих на то, что может быть предметом выборов на выборах, кто вообще может быть избран, каковы при этом его шансы. Ведь известно, что может быть не так, что «власть сама себя выбирает», но так, что, формально сохраняя принцип избираемости, «правящие силы руководят - или скрытно, или открыто, нахально и властно» самим избирательным процессом. При этом прежде, чем власть выберут, она сама создаст группы, которые на это «сориен-

\footnotetext{
1 Studia Politologiczne. Warszawa, 2020. Vol. 55.
} 
тирует материально или символическими жестами». Выборы часто именуют «праздником демократии», но в этот момент необходимо четко ответить и на многие вопросы, в т.ч. о политических последствиях принимаемых решений, о шансах на изменение расстановки политических сил и в связи с этим - на влияние на настроения и климат избирательной кампании, на выдвижение новых политических лидеров.

Первая часть публикации через показ актуального состояния польского общества и политических партий - как правящих, так и претендующих на власть раскрывает проблему «Выборы и механизмы распределения власти». Вторая часть «Кумуляция и монополизация власти. Предпосылки, проявления, механизмы» характеризует нарастание в стране авторитарных тенденций, отчуждения, чиновничьего вмешательства и мелочного регулирования политической, экономической, культурной, научной и даже частной жизни граждан. Подобные тенденции кризиса демократии, имеющие место в последние годы во всех постсоциалистических странах, рассматриваются как проявление определенных закономерностей. Отмечая успехи сравнительного анализа демократических и автократических (авторитарных и тоталитарных) режимов, польские политологи констатируют недостаточность разработки проблем природы, генезиса, морфологии и структурной обусловленности способов осуществления ими власти. Ставится задача изучения предпосылок и источников, диагностирования, квалификации и анализа этих явлений, их проявлений и механизмов.

Редакция журнала формулирует исследовательские темы для осмысления, обсуждения и последующего синтетического представления проблемы.

- Каким образом, в какой форме и в каких сферах, не только традиционно считающихся политическими, в настоящее время имеют место процессы концентрации и монополизации власти? Какие из них легко изучать эмпирически, а какие носят скрытый, неявный характер, иногда не осмысливаемый?

- Как связаны эти процессы с наблюдаемыми тенденциями отхода от неолиберальной демократии и автократическими тенденциями? Могут ли эти тенденции, и если да, то при каких условиях, вести к тоталитаризации власти и политики? Можно ли говорить о «третьей волне» отхода от демократии?

- В каком объеме и каким образом тенденции кумулирования, концентрации и монополизации власти могут иметь демократическую легитимацию и вырастать из механизмов демократических выборов?

- В какой степени антидемократические и автократические тенденции (ведущие к концентрации и монополизации власти) являются патологией современной политики, особенно ее функционирования? А может быть, они есть проявление более общих закономерностей? Какова их связь с кризисными явлениями современного глобального капитализма? Какова их связь с происходящей в мире перегруппировкой сил, а также империалистическим соперничеством различных средоточий и центров современной мировой системы?

- Чьи интересы, каких структур, строя или объективные выражают эти тенденции, каким большим социальным группам служат? Какие комплексы, агрегации или мультиплексы интересов служат стимулами наблюдающихся перемен в политических системах и механизмах функционирования власти в различных сферах жизни общества?

- Какие явления в области культуры и сознания, характерные для механизмов социальных и политических связей, являются коррелятором или доминантой тенденций монополизации и концентрации власти? Как эти явления проявляются в механизмах воспроизводства культурной и идеологической гегемонии, а также в механизмах воспроизводства структур и форм символической власти? 
- В какой степени инспирирующими исследования в области концентрации и монополизации власти могут быть результаты исследований в области естественных наук - социобиологии, эволюционной биологии, генетики, биологии мозга, мышления, процессов обучения и др.?

- Какие идеологические концепции и политические доктрины являются носителями таких современных тенденций? Выразителями сознания каких социальных групп являются эти идеологии, из чего вытекает их популярность, какие социальные функции они выполняют? Каковы социальные источники востребованности интеллектуальной легитимации потребности в концентрации власти и отхода от неолиберальной концепции и практики демократии? Что может ее заменить и почему?

- Какие теоретические модели, категории и понятия, какие теоретические схемы и парадигмальные перспективы сегодня особенно плодотворны при исследовании явлений концентрации и монополизации власти? Какие эпистемологические перспективы проявляют в этой сфере свою слабость и ограниченность? Как мы должны обогащать и изменять парадигмальные основы наших исследовательских рассуждений и практики? Где в этой сфере шансы и где угрозы для современной политологии, а также гуманитарных и общественных наук?

- Какие институциональные формы науки благоприятствуют эффективности и критицизму исследования концентрации и монополизации власти, а какие ослабляют ее способность критически анализировать социальные и политические явления и процессы? Какой является и какой должна быть роль политологии в области осмысления и критического анализа политических и идеологических функций научных исследований и их институционализации? Какова в этом контексте социальная миссия политологов и других исследователей социальной и политической жизни общества?

Считая перечисленные проблемы ключевыми и требующими дальнейшего углубленного изучения, журнал «Политологические исследования» обратился к специалистам с предложением подключиться к такой исследовательской программе.

\section{THE THESES OF THE JOURNAL «STUDIA POLITOLOGICZNE» ABOUT THE «ELECTION AND AUTHORITY» PROBLEM}

\footnotetext{
Abstract. The article analyzes the results of the parliamentary and presidential elections in 2015, the EU parliamentary elections in 2019 and parliamentary elections in 2019. The article presents the strategy used by Polish elites in the presidential and parliamentary campaigns. The main purpose of the paper is to present social engineering as a strategy of social management aimed at monopolizing political power. Social engineering strategies are based on the broad ambitions of steering systems and the long horizon of social changes planning. Social engineering here is closer to culture engineering, socialization, indoctrination, and aims not only at modifying the behavior of controlled systems, but above all at causing permanent changes in the structure of values, emotions and stereotypes.

Keywords: Poland, government, political mechanisms, elections in 2015-2019
} 